\title{
P085: Surveillance of drug-resistant Salmonella sp and Shigella sp infections in Rwanda
}

\author{
JB Gatabazi
}

From 2nd International Conference on Prevention and Infection Control (ICPIC 2013)

Geneva, Switzerland. 25-28 June 2013

\section{Introduction}

Salmonella $s p$. and Shigella sp infections are public health threat worldwide, particularly in Sub-Saharan Africa including in Rwanda. This study was done to identify Salmonella $s p$. and Shigella $s p$. currently circulating in Rwanda and determine their drug susceptibility pattern.

\section{Objectives}

To determine the prevalence of Salmonella spp. and Shigella spp. strains circulating in Rwanda and their susceptibilty pattern in Rwanda.

\section{Methods}

196 blood and 24 stool specimens from patients were analyzed in Laboratory of Rwanda for culture isolation, identification and drug-sensitivity testing.

\section{Results}

91 (92.2 \%) of them were identified as Salmonella enterica serovar Typhi, 10 were Shigella $s p$. The isolates were subsequently subjected to antibiotic susceptibility tests and the strains of $S$.Typhi isolates were found to be susceptible to cefotaxime (100\%), and ciprofloxacin (97.9\%) and resistant to nalidixic acid (89.4\%), cotrimoxazole (87.2\%). With regard to Shigella infections, the antibiotics which showed $100 \%$ susceptibility to all species identified were ciprofloxacine, cefotaxime, ceftazidine.

\section{Conclusion}

The prevalent Salmonella strain circulating in Rwanda is $S$.Typhi and two most useful drugs of choice to treat Salmonella sp. and Shigella sp. infections in Rwanda are cefotaxime and ciprofloxacin.

Laboratory Department, Rwanda Military Hospital Kigali, Kigali, Rwanda

\section{Disclosure of interest}

None declared.

Published: 20 June 2013

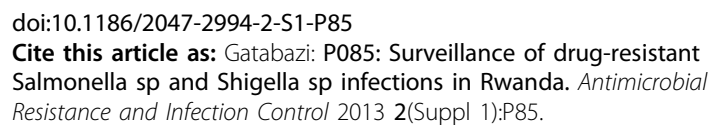

Cite this article as: Gatabazi: P085: Surveillance of drug-resistant Salmonella $\mathrm{sp}$ and Shigella sp infections in Rwanda. Antimicrobial Resistance and Infection Control 2013 2(Suppl 1):P85.

Submit your next manuscript to BioMed Central and take full advantage of:

- Convenient online submission

- Thorough peer review

- No space constraints or color figure charges

- Immediate publication on acceptance

- Inclusion in PubMed, CAS, Scopus and Google Scholar

- Research which is freely available for redistribution

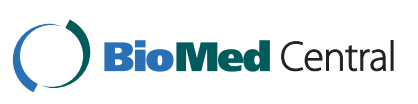

